\title{
Management of Elevated Blood Pressure After Stroke Thrombectomy for Anterior Circulation
}

This article was published in the following Dove Press journal:

Risk Management and Healthcare Policy

\author{
Kexin $\mathrm{Wu}^{\mathrm{l}, 2}$ \\ Zhencheng Xiong (D) ${ }^{3,4}$ \\ Yasuo Ding (iD) ${ }^{1,2}$ \\ 'Postgraduate School, Dalian Medical \\ University, Dalian, People's Republic of \\ China; ${ }^{2}$ Department of Neurosurgery, \\ Taizhou People's Hospital, Taizhou, \\ People's Republic of China; ${ }^{3}$ Institute of \\ Medical Technology, Peking University \\ Health Science Center, Beijing, People's \\ Republic of China; ${ }^{4}$ Peking University \\ Third Hospital, Beijing, People's Republic \\ of China
}

\begin{abstract}
Thrombectomy is superior to intravenous thrombolysis for patients with large vessel occlusion in acute ischemic stroke, but nearly half of the patients still experience poor functional outcomes. Elevated blood pressure (BP) is widely observed in acute ischemic stroke, and BP may be one of the modifiable parameters that can potentially influence the outcomes; however, only observational studies exist to support current guidelines, and the recommended range for BP after thrombectomy is too wide to meet the clinical requirement. Randomized controlled trials are therefore needed to better understand the relationship between BP and outcomes after thrombectomy. In this review, we introduce the current management of BP after thrombectomy and several aspects of postthrombectomy BP management that should be resolved in future clinical trials.
\end{abstract}

Keywords: acute ischemic stroke, mechanical thrombectomy, blood pressure, hypertension, outcomes

\section{Introduction}

Stroke is the third leading cause of death and DALYs (disability-adjusted life-years) globally, with a huge financial and social burden. ${ }^{1,2}$ Approximately $84.4 \%$ of the total number of prevalent strokes are ischemic strokes, ${ }^{3}$ and large vessel occlusion (LVO) is detected in more than one-third of acute ischemic strokes (AISs). ${ }^{4,5}$ Several randomized controlled trials (RCTs) have demonstrated the benefit of thrombectomy over intravenous thrombolysis, and the successful recanalization rates were improved to $70-80 \% ;^{6-10}$ however, nearly half of the eligible patients suffered from poor functional outcomes (mRS score $>2$ at 90 days) despite successful treatment with mechanical thrombectomy (MT). ${ }^{11}$

Various attempts have been made to ensure that patients with LVO are able to acquire maximum benefits from MT, including prehospital screening and dispatching systems to minimize transport time, emergent stroke severity rating scales and neuroimaging evaluations to promptly select qualified patients, and improved reperfusion therapy and catheters to ameliorate complete reperfusion rates. However, even in patients with acute cerebral LVO who are recanalized in a timely manner, the functional outcome is not always a success. Many factors can influence the functional outcome, but not all can be controlled. Acute stroke teams are incapable of determining the existing status of patients who are undergoing MT, such as the infarct and penumbra volume, collateral status, underlying diseases and time of stroke onset. Still, there are some parameters with the potential to improve functional outcomes that stroke teams can easily manipulate including anesthesia, oxygen, temperature, blood sugar and BP.
Correspondence: Yasuo Ding Department of Neurosurgery, Taizhou People's Hospital, Taizhou, People's Republic of China

Email doctordys@126.com
Risk Management and Healthcare Policy 2021:14 405-4I3 
As one of the modifiable parameters, BP elevation ( $>140$ / $90 \mathrm{mmHg}$ ) is widely detected during the early stage of ischemic stroke, occurring in approximately $80 \%$ of patients, ${ }^{12-14}$ which may serve as a compensatory response to better sustain brain perfusion. BP management in patients with LVO may be roughly divided into 3 sections: before, during and after MT. BP targets of the 3 periods are controversial, especially the third. Because sympathetic innervation is less common in the posterior circulation and would generate different $\mathrm{BP},{ }^{15}$ herein, we focus on the management of elevated BP after thrombectomy for anterior circulation.

\section{Guidelines and Practices}

\section{Guidelines}

The 2019 update to the 2018 AHA/ASA acute ischemic stroke management guideline recommends maintaining patient $\mathrm{BP}$ at $\leq 180 / 105 \mathrm{~mm} \mathrm{Hg}$ during and for $24 \mathrm{~h}$ after MT and $<180$ / $105 \mathrm{~mm} \mathrm{Hg}$ once successfully recanalized. ${ }^{16}$ The lack of RCTs in this management guideline is continuously confusing clinical practice; until now, no clear line has connected BP and outcome. Between 2010 and 2014, 5 RCTs (ESCAPE, REVASCAT, SWIFT PRIME, MR CLEAN and EXTEND IA) demonstrated the effectiveness of endovascular thrombectomy over standard care, but even in the protocols of these large RCTs, limited data on the optimal BP goal were reported. The ESCAPE protocol supplied additional instructions that proposed controlling systolic blood pressure (SBP) $\geq 150 \mathrm{mmHg}$ while the artery remained occluded and regulating the BP to a normal level once recanalized. The REVASCAT protocol recommended that BP should be tightly controlled to less than $185 / 110 \mathrm{mmHg}$ during the first $24 \mathrm{~h}$ and less than 160/90 $\mathrm{mmHg}$ if TICI $\geq 2 \mathrm{~b}$ is achieved. Additionally, DAWN and DEFUSE 3 extended the MT time window to more than 6 $\mathrm{h}$ with critical imaging selection criteria a few years later, but only DAWN additionally recommends maintaining $\mathrm{SBP}<140$ mmHg during the first $24 \mathrm{~h}$ after MT while reperfusion is achieved and keeping the BP target similar to the control group if reperfusion is not reached (Table 1). ${ }^{17}$

\section{Practices}

Current guidelines do not have explicit directions for post-MT BP management and cannot satisfy the needs of clinical practice given its wide range. Most stroke centers divide post-MT patients into a successful reperfusion group and an unsuccessful reperfusion group according to the perfusion status. Patients from each of the 2 groups would subsequently accept one of the following 7 target BP management schedules in light of the
Table I Blood Pressure Target in Thrombectomy-Based Randomized Controlled Trials

\begin{tabular}{|l|l|l|}
\hline RCT & Occlusion & Reperfusion \\
\hline ESCAPE & SBP $\geq 150 \mathrm{mmHg}$ & Normal \\
\hline REVASCAT & $<185 / 110 \mathrm{mmHg}$ & $\mathrm{BP}<160 / 90 \mathrm{mmHg}$ \\
\hline SWIFT PRIME & $\leq 180 / 105 \mathrm{~mm} \mathrm{Hg}$ \\
\hline MR CLEAN & Not mentioned & \\
\hline EXTEND IA & Not mentioned & \\
\hline DAWN & Similar as control group & SBP $<140 \mathrm{mmHg}$ \\
\hline DEFUSE 3 & Not mentioned \\
\hline
\end{tabular}

Abbreviations: $\mathrm{RCT}$, randomized controlled trial; $\mathrm{BP}$, blood pressure; SBP, systolic blood pressure.

respective therapeutic regimens: $\mathrm{SBP}<120 \mathrm{~mm} \mathrm{Hg}$, 120-139 mm Hg, 140-159 mm Hg, 160-179 mm Hg, $\leq 180 \mathrm{~mm} \mathrm{Hg}, \leq 220 \mathrm{~mm} \mathrm{Hg}$, and an individualized group. A survey investigating the current application of the 2018 AHA/ASA guidelines for BP management after MT found that most institutions (91\%) would only individually target post-MT SBP but not diastolic blood pressure (DBP) or mean arterial pressure (MAP). Moreover, $27.6 \%$ of institutions would aim for SBP at any value $\leq 180 \mathrm{~mm} \mathrm{Hg}$ in patients with successful reperfusion (mTICI 2b-3), which was also recommend by the guideline, and the number increased to $43.1 \%$ if reperfusion was not achieved successfully (mTICI 0-2a); the remaining institutions would follow their own protocol. ${ }^{18}$ The results of this survey typically reflect the inconformity between current practice and guidelines.

The recommendations on BP treatment after thrombectomy in AIS are inconsistent because it remains unclear whether BP elevation is a cause or just a poor outcome marker. Supposing that BP elevation is a marker of a poor outcome, wide ranging management is readily acceptable; however, if the reverse is true, and BP elevation is the cause of a poor outcome, more fastidious and individual management is required.

\section{Pathophysiology} Collaterals and BP

Ischemic stroke is a dynamic process that cannot be completed in one attack; 1.9 million neurons and 1.8 days of healthy life pass away every minute in AIS if reperfusion is not reached in a timely manner. ${ }^{19,20}$ Ischemia is characterized as cerebral blood flow $(\mathrm{CBF})<20 \mathrm{~mL} / 100 \mathrm{~g} / \mathrm{min}$, and when the blood 
flow of that area drops below 10 or $12 \mathrm{~mL} / 100 \mathrm{~g} / \mathrm{min}$, the infarction core begins to take shape. ${ }^{21} \mathrm{CBF}$ recovery is needed as soon as possible before cell death occurs and to save the penumbra. The penumbra is an ischemic ring surrounding the infarct core with the potential for recovery and is destined for cell death without reperfusion. First conceptualized through animal models in 1977 by Astrup et al, ${ }^{22}$ the penumbra was defined as salvageable brain tissue with the threshold between electric failure and energy failure in $1981 .^{23}$ Since then, different animal models of cerebral ischemia used to determine the essential CBF of the penumbra have been developed. ${ }^{24-29}$ With the development of imaging techniques, the penumbra was later detected by PET in animal models and humans, ${ }^{30-32}$ while MRI and CTP have been more widely used to discriminate the penumbra in clinical practice due to the advantages of rapid diagnosis and easy acquisition.

The penumbra is still salvageable mainly owing to collateral circulation, but the relationship between BP and collaterals has not been rigorously studied. A retrospective cohort study showed that higher arterial BP was associated with improved leptomeningeal collaterals. ${ }^{33}$ Cerebral flow augmentation resulting from increased $\mathrm{BP}$ is of vital importance in protecting the penumbra before recanalization, which was demonstrated by retrospective studies showing that decreased BP during MT was associated with poor outcomes, and BP elevation is common prior to recanalization. $^{34-38}$ An ongoing RCT (NCT04218773) is attempting to confirm the positive effect of BP elevation through SBP augmentation by $20 \%$ to at least $160 \mathrm{mmHg}$ until blood vessel recanalization is accomplished or MT is completed. From this point of view, it is not surprising that higher BP or even induced hypertension is acceptable before recanalization to preserve the penumbra. The post hoc analysis of the ASTER trial found that BP variation during MT correlated with poor outcomes irrespective of any collateral status. ${ }^{39}$ For patients with successful reperfusion after MT, higher BP variability was observed to have a harmful influence on outcomes in those with poor collaterals. ${ }^{40}$

\section{Cerebral Autoregulation and BP}

Under normal circumstances, cerebral autoregulation (CA) plays a significant role in sustaining $\mathrm{CBF}$, while arterial blood pressure (ABP) fluctuates. ${ }^{41}$ In AIS, CA functions in preventing hyperperfusion of the penumbra. The ischemic brain is more vulnerable to changes in SBP after dysfunctional autoregulation; ${ }^{42,43}$ hence, once $\mathrm{CA}$ is impaired, ABP fluctuation may do more harm to the ischemic area. The impairment of dynamic CA has been shown and reported in several studies using different assessment methods, and its duration may last for at least one or two weeks. ${ }^{44-48}$ When exploring the optimal $\mathrm{BP}$ in post-MT patients, the impact of CA must not be overlooked. In addition, considering the duration of CA impairment, meticulous BP management may be performed for at least one or two weeks.

Myogenic, neurogenic and metabolic mechanisms were all observed in $\mathrm{CA}$, none of which would act alone in $\mathrm{BP}$ regulation. Myogenic mechanisms may be more efficient due to the rapid changes in arterial pressure in AIS. ${ }^{49}$ A study using a murine model demonstrated that longer reperfusion was accompanied by decreased myogenic reactivity, ${ }^{50}$ which would result in CA impairment. However, heterogeneity exists in myogenic tone between different cerebral arteries that participate in autoregulation, ${ }^{51}$ and the exact mechanisms of autoregulation in AIS are still unclear. Several approaches are used in clinical practice for evaluating $\mathrm{CA}$ and demonstrating an exact linear relationship between $\mathrm{BP}$ and $\mathrm{CBF}$, but until now, no gold standard exists for ideally assessing CA. On account of the complicated mechanisms of CA and the absence of standard assessment for CA, the first-best BP to ensure felicitous $\mathrm{CBF}$ is still a challenge.

\section{Ischemic Reperfusion Injury and BP}

Reperfusion treatment is complicated by ischemic reperfusion injury because blood flow restoration and reoxygenation may paradoxically aggravate damage to ischemic brain tissue. The mechanisms for ischemic reperfusion injury include processes of vascular leakage, no reflow phenomenon, cell death programs, autoimmunity, transcriptional reprogramming and innate and adaptive immune activation, ${ }^{52}$ which may eventually impair the blood-brain barrier (BBB). ${ }^{53}$ The subsequent clinical manifestation is brain edema and hemorrhage, from which patients may not benefit from recanalization or even undergo an aggravated process. Both edema and hemorrhage can cause additional compression, ischemia and toxicityrelated injury.

Therefore, elevated BP not only improves CBF in ischemic areas but also produces excessive impairment to the brain once reperfusion is reached and the $\mathrm{BBB}$ is disrupted. BP management for patients after stroke thrombectomy should balance hypoperfusion and hyperperfusion. The ischemic reperfusion injury models support proper BP reduction in patients with AIS after reperfusion and indicate that simple antihypertensive treatment may be insufficient.

\section{Influence of BP on Outcomes}

Study opinions are divergent about the relationship between $\mathrm{BP}$ and outcomes in AIS, and a U- or J-shaped effect of BP was 


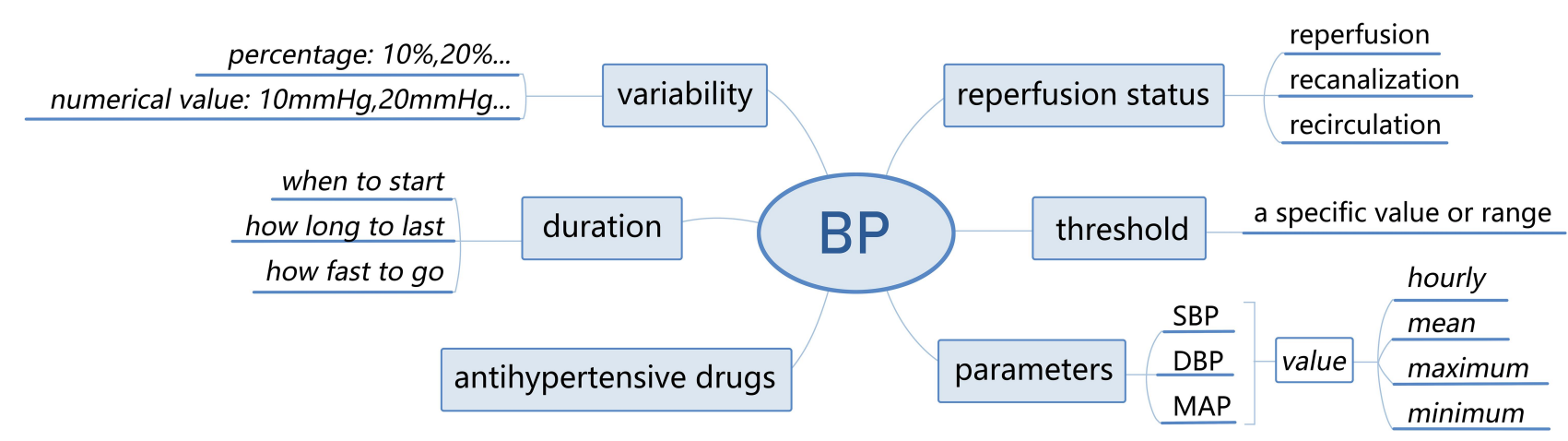

Figure I Several aspects of blood pressure management are to be solved after stroke thrombectomy. Abbreviations: BP, blood pressure; SBP, systolic blood pressure; DBP, diastolic blood pressure; MAP, mean arterial pressure.

widely discovered in retrospective studies. ${ }^{13,54,55}$ Prior RCTs attempting to find a relationship between BP lowering and outcomes in acute strokes raised debate, ${ }^{56-67}$ with some demonstrating promising effects of BP lowering, while others did not. These RCTs were not very comparable because most did not share the same onset time, therapeutic schedule, and type, duration and dosage of antihypertensive drugs. A metaanalysis found conspicuous heterogeneity among these studies and concluded a neutral effect of BP lowering in ischemic strokes ${ }^{68}$ which was not convincing enough for patients with MT. The included studies were not particular to participants treated with MT; therefore, more precise subgrouping methods surfaced according to different types of stroke, treatment methods and stages.

Elevated BP before and during MT is universally considered to be appropriate even without powerful evidence, and hypotension was shown to be connected with poor outcomes in some retrospective studies, ${ }^{34-38}$ but in regard to post-MT BP management, clinical decision making may be more complex. No completed clinical RCT exists to guide BP management after MT. A randomized trial using murine models demonstrated the favorable effect of BP lowering after recanalization, ${ }^{69}$ while a post hoc analysis of the SIESTA trial found no correlation between BP lowering and short- or long-term functional outcomes. ${ }^{70}$ Moreover, in line with some retrospective studies that found that hypertension is associated with worse outcomes, ${ }^{71-75}$ elevated BP after MT may need to be lowered. All of these studies are not BP-based interventional studies; RCTs are needed, and more attention should be paid to several aspects as follows when exploring the influence of BP on patient outcomes after MT (Figure 1).

\section{Reperfusion Status}

Once thrombectomy is completed, regardless of whether reperfusion is reached, the postthrombectomy period begins. During this period, recanalization status has an immense effect on BP after MT. John et al found that SBP may drop spontaneously after MT irrespective of the recanalization status, and in patients with unsuccessful recanalization, SBP may decrease more slightly but eventually arrive at levels similar to patients after successful recanalization within $24 \mathrm{~h}^{76}$ Martins et al discovered a linear relationship between SBP and functional outcome in recanalized patients, in which higher SBP was correlated with poor outcomes, while in unsuccessful recanalized patients, the association was J-shaped. ${ }^{77}$ In contrast, another study with a larger sample size proposed a linear model to better determine the relevance between functional outcome and SBP for unsuccessfully recanalized patients. ${ }^{78}$ Ignoring the exact model, it was widely accepted that higher SBP was associated with poor outcomes in patients with successful recanalization; ${ }^{79}$ in patients with unsuccessful recanalization, CA should increase SBP to maintain CBF for the ischemic tissue, and permissive hypertension may be more appropriate.

Successful reopening of occluded arteries (recanalization) will not always lead to complete restoration of microcirculation (reperfusion), ${ }^{80-82}$ and reperfusion performs better in predicting the outcomes. ${ }^{83}$ Therefore, the reperfusion status should be more significant than the recanalization status in BP management. However, recanalization is used more frequently in clinical practice, and the concept between recanalization and reperfusion is not well understood or illustrated clearly. In addition, recirculation has recently been raised again to better explain brain injury after AIS, ${ }^{84}$ which additionally involves the venous systems, whereas the specific mechanism of recirculation is less explored. More studies are needed to better understand the effect of recanalization, reperfusion and recirculation and to further distinguish their differences regarding BP management after MT. 


\section{Threshold}

Whether any optimal threshold exists for post-MT BP after reperfusion status is unclear. A prospective cohort study (BEST) reported that a peak SBP of $158 \mathrm{mmHg}$ may be the best-rank threshold without adjusted analysis. ${ }^{85}$ Goyal et al found that $\mathrm{BP}<160 / 90 \mathrm{mmHg}$ within $24 \mathrm{~h}$ after MT resulted in less mortality, ${ }^{71}$ while Ding et al indicated that $\mathrm{SBP} \leq 140$ $\mathrm{mmHg}$ was related to better outcomes and lower parenchymal hemorrhage. ${ }^{75}$ Matusevicius et al reported that $100 \leq \mathrm{SBP} \leq 119$ $\mathrm{mmHg}$ contributed to better functional outcomes in patients with successful recanalization, and the range was 120-139 $\mathrm{mmHg}$ in patients with unsuccessful recanalization. ${ }^{78}$ Maier et al found that a maximum SBP of $159 \mathrm{mmHg}$ was the best cutoff for patients with successful recanalization, while a higher SBP was associated with poor functional outcomes. ${ }^{79}$ If any BP threshold for patients after MT exists, it may be a specific value or a range with an upper and lower cutoff based on the reperfusion status. Future studies are needed to identify the threshold to better guide practice.

\section{Parameter}

The final determination of the optimal BP threshold can never circumvent SBP, DBP and MAP, and the hourly, maximum, minimum, and mean values of each of these parameters are essential while turning point for the threshold. SBP is more adequately handled than MAP or DBP in general, ${ }^{18}$ but whether SBP is more important than MAP or DBP remains unknown. Mistry et al demonstrated that the maximum SBP was directly associated with outcomes, while other parameters did not affect outcomes. ${ }^{72}$ The prospective cohort study (BEST) also demonstrated the potency of maximal SBP but not DBP or MAP. ${ }^{75}$ Moreover, Martins et al reported the usefulness of both SBP and DBP in predicting outcomes. ${ }^{77}$ Future studies should cover all of the parameters to determine the most appropriate one.

\section{Variability}

After a BP threshold with a detailed parameter is approximately determined, we may encounter another predicament: should we control the BP to a certain point or consider BP variability (BPV)? For instance, if the target threshold of SBP is $140 \mathrm{mmHg}$, bringing a primary SBP of $180 \mathrm{mmHg}$ down to this level may differ from reducing a primary SBP of 160 $\mathrm{mmHg}$ to this target within the same time period. A larger BPV was shown to be associated with worse outcomes in patients with $\mathrm{AIS},{ }^{86-92}$ and this was also observed in the subgroup of patients with stroke thrombectomy. ${ }^{40,93-95}$
Clinicians may have to choose whether to reduce BP to some degree or maintain a relatively stable BP. A stable BP may be defined as fluctuation within a percentage or a detailed number, such as $10 \%$ or $10 \mathrm{mmHg}$. BP management in patients with hypertension after thrombectomy should never neglect the influence of BPV.

\section{Duration}

The next obstacle is the duration of strict BP management after MT, in which three main aspects need to be solved: start time, duration and speed. Antihypertensive treatment may start immediately after thrombectomy once patients suffer from hypertension in the intensive care unit, but during the delivery process, which primarily occurs from the catheter room to the intensive unit or, in some cases, from the catheter room to the CT or MRI room and then to the intensive room, antihypertensive treatment may not start. Furthermore, in accordance with the duration of cerebral CA impairment, particular BP management should last for at least one or two weeks; ${ }^{44} 48$ in reality, $24 \mathrm{~h}$ after MT is usually evaluated and recognized as the key period in some studies, ${ }^{40,71,94}$ and a retrospective study even found that the first $6 \mathrm{~h}$ was the pivotal interval. ${ }^{74}$ Regarding speed, there is no clear recommendation on the rate of $\mathrm{BP}$ decline; in other words, whether BP should be reduced to a threshold intensively within minutes or dilatorily within hours is unclear.

\section{Antihypertensive Drugs}

No consensus has been reached on the best antihypertensive drug(s), and intravenous administration of drugs with quick action and short duration is universally accepted. Labetalol, hydralazine, nicardipine, clevidipine, hydralazine, enalaprilat and sodium nitroprusside are recommended by the AHA/ASA guidelines for all types of hypertension, ${ }^{16}$ while urapidil is widely used in Europe and Asia. For patients with elevated BP after MT, the top priority may be the safety and efficacy of the antihypertensive treatment. More research is warranted to ascertain the most efficacious antihypertensive drug.

\section{Conclusion}

Elevated BP management must balance between increasing cerebral perfusion and preventing reperfusion injury. To realize this goal, a better understanding of pathophysiology is imperative. Collaterals, penumbra, infarct core, CA, preexisting hypertension and other basic statuses all need to be noted, Interactions among all these factors may influence the effect of BP on outcomes after MT, but the relationship between these factors and BP is 
not well established. The unclear pathophysiology of the effect of BP on outcomes complicates the function of BP after MT. The efficacy reported in observational studies was unable to meet clinical requirements; therefore, BPbased RCTs are actively needed to provide guidance on BP management in patients after stroke thrombectomy. During the procedure, reperfusion status should be carefully considered. The threshold, parameters, variability and duration for BP and antihypertensive drugs need to be further evaluated.

\section{Author Contributions}

All authors made a significant contribution to the work reported, whether that is in the conception, study design, execution, acquisition of data, analysis and interpretation, or in all these areas; took part in drafting, revising or critically reviewing the article; gave final approval of the version to be published; have agreed on the journal to which the article has been submitted; and agree to be accountable for all aspects of the work.

\section{Disclosure}

The authors report no conflicts of interest in this work.

\section{References}

1. Kyu HH, Abate D, Abate KH, et al. Global, regional, and national disability-adjusted life-years (DALYs) for 359 diseases and injuries and healthy life expectancy (HALE) for 195 countries and territories, 1990-2017: a systematic analysis for the Global Burden of Disease Study 2017. Lancet. 2018;392(10159):1859-1922.

2. Roth GA, Abate D, Abate KH, et al. Global, regional, and national age-sex-specific mortality for 282 causes of death in 195 countries and territories, 1980-2017: a systematic analysis for the Global Burden of Disease Study 2017. Lancet. 2018;392(10159):1736-1788.

3. Johnson CO, Nguyen M, Roth GA. Global, regional, and national burden of stroke, 1990-2016: a systematic analysis for the Global Burden of Disease Study 2016. Lancet Neurol. 2019;18(5):439-458. doi:10.1016/S1474-4422(19)30034-1

4. Lima FO, Silva GS, Furie KL, et al. Field assessment stroke triage for emergency destination: a simple and accurate prehospital scale to detect large vessel occlusion strokes. Stroke. 2016;47(8):1997-2002. doi:10.1161/STROKEAHA.116.013301

5. Malhotra K, Gornbein J, Saver JL. Ischemic strokes due to large-vessel occlusions contribute disproportionately to stroke-related dependence and death: a review. Front Neurol. 2017;8:651. doi:10.3389/ fneur.2017.00651

6. Saver JL, Goyal M, Bonafe A, et al. Stent-retriever thrombectomy after intravenous t-PA vs. t-PA alone in stroke. $N$ Engl $J$ Med. 2015;372(24):2285-2295. doi:10.1056/NEJMoa1415061

7. Jovin TG, Chamorro A, Cobo E, et al. Thrombectomy within 8 hours after symptom onset in ischemic stroke. $N$ Engl J Med. 2015;372 (24):2296-2306. doi:10.1056/NEJMoa 1503780

8. Goyal M, Demchuk AM, Menon BK, et al. Randomized assessment of rapid endovascular treatment of ischemic stroke. $N$ Engl $J$ Med. 2015;372(11):1019-1030. doi:10.1056/NEJMoa1414905
9. Campbell BCV, Mitchell PJ, Kleinig TJ, et al. Endovascular therapy for ischemic stroke with perfusion-imaging selection. $N$ Engl J Med. 2015;372(11):1009-1018. doi:10.1056/NEJMoa1414792

10. Berkhemer OA, Fransen PSS, Beumer D, et al. A randomized trial of intraarterial treatment for acute ischemic stroke. $N$ Engl J Med. 2015;372(1):11-20. doi:10.1056/NEJMoa1411587

11. Goyal M, Menon BK, van Zwam WH, et al. Endovascular thrombectomy after large-vessel ischaemic stroke: a meta-analysis of individual patient data from five randomised trials. Lancet. 2016;387 (10029):1723-1731. doi:10.1016/S0140-6736(16)00163-X

12. Qureshi AI, Ezzeddine MA, Nasar A, et al. Prevalence of elevated blood pressure in 563704 adult patients with stroke presenting to the ED in the United States. Am J Emerg Med. 2007;25(1):32-38. doi:10.1016/j.ajem.2006.07.008

13. Leonardi-Bee J, Bath PMW, Phillips SJ, et al. Blood pressure and clinical outcomes in the international stroke trial. Stroke. 2002;33 (5):1315-1320. doi:10.1161/01.STR.0000014509.11540.66

14. Wallace JD, Levy LL. Blood pressure after stroke. JAMA. 1981;246 (19):2177-2180. doi:10.1001/jama.1981.03320190035023

15. Edvinsson L, Owman C, Sjöberg NO. Autonomic nerves, mast cells, and amine receptors in human brain vessels. A histochemical and pharmacological study. Brain Res. 1976;115(3):377-393. doi:10.1016/0006-8993(76)90356-5

16. Powers WJ, Rabinstein AA, Ackerson T, et al. Guidelines for the early management of patients with acute ischemic stroke: 2019 update to the 2018 guidelines for the early management of acute ischemic stroke: a guideline for healthcare professionals from the American Heart Association/American Stroke Association. Stroke. 2019;50(12):e344 e418. doi:10.1161/STR.0000000000000211

17. Nogueira RG, Jadhav AP, Haussen DC, et al. Thrombectomy 6 to 24 hours after stroke with a mismatch between deficit and infarct. N Engl J Med. 2018;378(1):11-21. doi:10.1056/NEJMoa1706442

18. Mistry EA, Mayer SA, Khatri P. Blood pressure management after mechanical thrombectomy for acute ischemic stroke: a survey of the StrokeNet sites. J Stroke Cerebrovasc Dis. 2018;27(9):2474-2478. doi:10.1016/j.jstrokecerebrovasdis.2018.05.003

19. Meretoja A, Keshtkaran M, Saver JL, et al. Stroke thrombolysis: save a minute, save a day. Stroke. 2014;45(4):1053-1058. doi:10.1161/ STROKEAHA.113.002910

20. Saver JL. Time is brain-quantified. Stroke. 2006;37(1):263-266. doi:10.1161/01.STR.0000196957.55928.ab

21. Hakim A. Ischemic penumbra: the therapeutic window. Neurology. 1998;51(Issue 3, Supplement 3):S44-S46. doi:10.1212/ WNL.51.3_Suppl_3.S44

22. Astrup J, Symon L, Branston NM, et al. Cortical evoked potential and extracellular $\mathrm{K}+$ and $\mathrm{H}+$ at critical levels of brain ischemia. Stroke. 1977;8(1):51-57. doi:10.1161/01.STR.8.1.51

23. Astrup J, Siesjö BK, Symon L. Thresholds in cerebral ischemia - the ischemic penumbra. Stroke. 1981;12(6):723-725. doi:10.1161/01. STR.12.6.723

24. Macrae IM, Robinson MJ, Graham DI, et al. Endothelin-1-induced reductions in cerebral blood flow: dose dependency, time course, and neuropathological consequences. J Cereb Blood Flow Metab. 1993;13(2):276-284. doi:10.1038/jcbfm.1993.34

25. Tamura A, Graham DI, McCulloch J, et al. Focal cerebral ischaemia in the rat: 1 . Description of technique and early neuropathological consequences following middle cerebral artery occlusion. J Cereb Blood Flow Metab. 1981;1(1):53-60. doi:10.1038/jcbfm.1981.6

26. Zhang L, Zhang RL, Jiang Q, et al. Focal embolic cerebral ischemia in the rat. Nat Protoc. 2015;10(4):539-547. doi:10.1038/nprot.2015.036

27. Watson BD, Dietrich WD, Busto R, et al. Induction of reproducible brain infarction by photochemically initiated thrombosis. Ann Neurol. 1985;17(5):497-504. doi:10.1002/ana.410170513

28. Orset C, Macrez R, Young AR, et al. Mouse model of in situ thromboembolic stroke and reperfusion. Stroke. 2007;38(10):2771-2778. doi:10.1161/STROKEAHA.107.487520 
29. Longa EZ, Weinstein PR, Carlson S, et al. Reversible middle cerebral artery occlusion without craniectomy in rats. Stroke. 1989;20 (1):84-91. doi:10.1161/01.STR.20.1.84

30. Heiss W-D, Graf R, Wienhard K, et al. Dynamic penumbra demonstrated by sequential multitracer PET after middle cerebral artery occlusion in cats. J Cereb Blood Flow Metab. 1994;14(6):892-902. doi:10.1038/jcbfm.1994.120

31. Marchal G, Rioux P, Petit-Tabou MC, et al. PET imaging of cerebral perfusion and oxygen consumption in acute ischaemic stroke: relation to outcome. Lancet. 1993;341(8850):925-927. doi:10.1016/01406736(93)91214-7

32. Touzani O, Young AR, Derlon J-M, et al. Sequential studies of severely hypometabolic tissue volumes after permanent middle cerebral artery occlusion. A positron emission tomographic investigation in anesthetized baboons. Stroke. 1995;26(11):2112-2119. doi:10.1161/01.STR.26.11.2112

33. Jiang B, Churilov L, Kanesan L, et al. Blood pressure may be associated with arterial collateralization in anterior circulation ischemic stroke before acute reperfusion therapy. J Stroke. 2017;19 (2):222-228. doi: $10.5853 /$ jos.2016.01739

34. Maïer B, Fahed R, Khoury N, et al. Association of blood pressure during thrombectomy for acute ischemic stroke with functional outcome: a systematic review. Stroke. 2019;50(10):2805-2812. doi:10.1161/STROKEAHA.119.024915

35. Treurniet KM, Berkhemer OA, Immink RV, et al. A decrease in blood pressure is associated with unfavorable outcome in patients undergoing thrombectomy under general anesthesia. J Neurointerv Surg. 2018;10(2):107-111. doi:10.1136/neurintsurg-2017-012988

36. Petersen NH, Ortega-Gutierrez S, Wang A, et al. Decreases in blood pressure during thrombectomy are associated with larger infarct volumes and worse functional outcome. Stroke. 2019;50 (7):1797-1804. doi:10.1161/STROKEAHA.118.024286

37. Whalin M, Halenda KM, Haussen DC, et al. Even small decreases in blood pressure during conscious sedation affect clinical outcome after stroke thrombectomy: an analysis of hemodynamic thresholds. AJNR Am J Neuroradiol. 2017;38(2):294-298. doi:10.3174/ajnr.A4992

38. Löwhagen Hendén P, Rentzos A, Karlsson J-E, et al. Hypotension during endovascular treatment of ischemic stroke is a risk factor for poor neurological outcome. Stroke. 2015;46(9):2678-2680. doi:10.1161/STROKEAHA.115.009808

39. Maïer B, Dargazanli C, Bourcier R, et al. Effect of steady and dynamic blood pressure parameters during thrombectomy according to the collateral status. Stroke. 2020;51(4):1199-1206. doi:10.1161/ STROKEAHA.119.026769

40. Chang J, Jeon S-B, Jung C, et al. Postreperfusion blood pressure variability after endovascular thrombectomy affects outcomes in acute ischemic stroke patients with poor collateral circulation. Front Neurol. 2019;10:346. doi:10.3389/fneur.2019.00346

41. Strandgaard S, Paulson OB. Cerebral autoregulation. Stroke. 1984;15 (3):413-416. doi:10.1161/01.STR.15.3.413

42. Powers WJ. Acute hypertension after stroke: the scientific basis for treatment decisions. Neurology. 1993;43(3 Pt 1):461-467. doi:10.1212/WNL.43.3 Part 1.461

43. Jusufovic M, Sandset EC, Bath PMW, et al. Effects of blood pressure lowering in patients with acute ischemic stroke and carotid artery stenosis. Int J Stroke. 2015;10(3):354-359. doi:10.1111/ijs.12418

44. Powers WJ, Videen TO, Diringer MN, et al. Autoregulation after ischaemic stroke. J Hypertens. 2009;27(11):2218-2222. doi:10.1097/ HJH.0b013e328330a9a7

45. Dawson SL, Blake MJ, Panerai RB, et al. Dynamic but not static cerebral autoregulation is impaired in acute ischaemic stroke. Cerebrovasc Dis. 2000;10(2):126-132. doi:10.1159/000016041

46. Eames PJ, Blake MJ, Dawson SL, et al. Dynamic cerebral autoregulation and beat to beat blood pressure control are impaired in acute ischaemic stroke. J Neurol Neurosurg Psychiatry. 2002;72 (4):467-472. doi:10.1136/jnnp.72.4.467
47. Immink RV, van Montfrans GA, Stam J, et al. Dynamic cerebral autoregulation in acute lacunar and middle cerebral artery territory ischemic stroke. Stroke. 2005;36(12):2595-2600. doi:10.1161/01. STR.0000189624.06836.03

48. Petersen NH, Ortega-Gutierrez S, Reccius A, et al. Dynamic cerebral autoregulation is transiently impaired for one week after large-vessel acute ischemic stroke. Cerebrovasc Dis. 2015;39(2):144-150. doi: $10.1159 / 000368595$

49. Hamner JW, Tan CO. Relative contributions of sympathetic, cholinergic, and myogenic mechanisms to cerebral autoregulation. Stroke. 2014;45(6):1771-1777. doi:10.1161/STROKEAHA.114.005293

50. Cipolla MJ, McCall AL, Lessov N, et al. Reperfusion decreases myogenic reactivity and alters middle cerebral artery function after focal cerebral ischemia in rats. Stroke. 1997;28(1):176-180. doi:10.1161/01.STR.28.1.176

51. Cipolla MJ, Li R, Vitullo L. Perivascular innervation of penetrating brain parenchymal arterioles. J Cardiovasc Pharmacol. 2004;44 (1):1-8. doi:10.1097/00005344-200407000-00001

52. Eltzschig HK, Eckle T. Ischemia and reperfusion-from mechanism to translation. Nat Med. 2011;17(11):1391-1401. doi:10.1038/ nm. 2507

53. Yang GY, Betz AL. Reperfusion-induced injury to the blood-brain barrier after middle cerebral artery occlusion in rats. Stroke. 1994;25(8):1658-64; discussion 1664-5. doi:10.1161/01. STR.25.8.1658

54. Castillo J, Leira R, Garcia MM, et al. Blood pressure decrease during the acute phase of ischemic stroke is associated with brain injury and poor stroke outcome. Stroke. 2004;35(2):520-526. doi:10.1161/01. STR.0000109769.22917.B0

55. Okumura K, Ohya Y, Maehara A, et al. Effects of blood pressure levels on case fatality after acute stroke. J Hypertens. 2005;23 (6):1217-1223. doi:10.1097/01.hjh.0000170385.76826.4a

56. Sandset EC, Bath PM, Boysen G, et al. The angiotensin-receptor blocker candesartan for treatment of acute stroke (SCAST): a randomised, placebo-controlled, double-blind trial. Lancet. 2011;377(9767):741-750. doi:10.1016/S0140-6736(11)60104-9

57. Potter JF, Robinson TG, Ford GA, et al. Controlling hypertension and hypotension immediately post-stroke (CHHIPS): a randomised, placebo-controlled, double-blind pilot trial. Lancet Neurol. 2009;8 (1):48-56. doi:10.1016/S1474-4422(08)70263-1

58. Ahmed N, Näsman P, Wahlgren NG. Effect of intravenous nimodipine on blood pressure and outcome after acute stroke. Stroke. 2000;31(6):1250-1255. doi:10.1161/01.STR.31.6.1250

59. Bath PMW, Martin RH, Palesch Y, et al. Effect of telmisartan on functional outcome, recurrence, and blood pressure in patients with acute mild ischemic stroke: a PRoFESS subgroup analysis. Stroke. 2009;40(11):3541-3546. doi:10.1161/STROKEAHA.109.555623

60. Robinson TG, Potter JF, Ford GA, et al. Effects of antihypertensive treatment after acute stroke in the Continue or Stop Post-Stroke Antihypertensives Collaborative Study (COSSACS): a prospective, randomised, open, blinded-endpoint trial. Lancet Neurol. 2010;9 (8):767-775. doi:10.1016/S1474-4422(10)70163-0

61. He J, Zhang Y, Xu T, et al. Effects of immediate blood pressure reduction on death and major disability in patients with acute ischemic stroke: the CATIS randomized clinical trial. JAMA. 2014;311(5):479-489. doi:10.1001/jama.2013.282543

62. ENOS Trial Investigators. Efficacy of nitric oxide, with or without continuing antihypertensive treatment, for management of high blood pressure in acute stroke (ENOS): a partial-factorial randomised controlled trial. Lancet. 2015;385(9968):617-628. doi:10.1016/S01406736(14)61121-1

63. Ankolekar S, Fuller M, Cross I, et al. Feasibility of an ambulance-based stroke trial, and safety of glyceryl trinitrate in ultra-acute stroke: the rapid intervention with glyceryl trinitrate in hypertensive stroke trial (RIGHT, ISRCTN66434824). Stroke. 2013;44(11):3120-3128. doi:10.1161/STROKEAHA.113.001301 
64. Eveson DJ, Robinson TG, Potter JF. Lisinopril for the treatment of hypertension within the first 24 hours of acute ischemic stroke and follow-up. Am J Hypertens. 2007;20(3):270-277. doi:10.1016/j. amjhyper.2006.08.005

65. Oh MS, Yu K-H, Hong K-S, et al. Modest blood pressure reduction with valsartan in acute ischemic stroke: a prospective, randomized, open-label, blinded-end-point trial. Int J Stroke. 2015;10(5):745-751. doi:10.1111/ijs. 12446

66. Kaste M, Fogelholm R, Erilä T, et al. A randomized, double-blind, placebo-controlled trial of nimodipine in acute ischemic hemispheric stroke. Stroke. 1994;25(7):1348-1353. doi:10.1161/01.STR.25.7.1348

67. Horn J, de Haan RJ, Vermeulen M, et al. Very Early Nimodipine Use in Stroke (VENUS): a randomized, double-blind, placebo-controlled trial. Stroke. 2001;32(2):461-465. doi:10.1161/01.STR.32.2.461

68. Lee M, Ovbiagele B, Hong K-S, et al. Effect of blood pressure lowering in early ischemic stroke: meta-analysis. Stroke. 2015;46 (7):1883-1889. doi:10.1161/STROKEAHA.115.009552

69. Elewa HF, Kozak A, Johnson MH, et al. Blood pressure lowering after experimental cerebral ischemia provides neurovascular protection. J Hypertens. 2007;25(4):855-859. doi:10.1097/HJH.0b013e3280149708

70. Schönenberger S, Uhlmann L, Ungerer M, et al. Association of blood pressure with short- and long-term functional outcome after stroke thrombectomy: post hoc analysis of the SIESTA trial. Stroke. 2018;49 (6):1451-1456. doi:10.1161/STROKEAHA.117.019709

71. Goyal N, Tsivgoulis G, Pandhi A, et al. Blood pressure levels post mechanical thrombectomy and outcomes in large vessel occlusion strokes. Neurology. 2017;89(6):540-547. doi:10.1212/ WNL.0000000000004184

72. Mistry EA, Mistry AM, Nakawah MO, et al. Systolic blood pressure within 24 hours after thrombectomy for acute ischemic stroke correlates with outcome. J Am Heart Assoc. 2017;6(5):5. doi:10.1161/ JAHA.117.006167

73. Anadani M, Arthur AS, Alawieh A, et al. Blood pressure reduction and outcome after endovascular therapy with successful reperfusion: a multicenter study. J Neurointerv Surg. 2020;12(10):932-936.

74. Chu HJ, Lin $\mathrm{CH}$, Chen $\mathrm{CH}$, et al. Effect of blood pressure parameters on functional independence in patients with acute ischemic stroke in the first 6 hours after endovascular thrombectomy. $J$ Neurointerv Surg. 2020;12(10):937-941.

75. Ding X, Xu C, Zhong W, et al. Association of maximal systolic blood pressure with poor outcome in patients with hyperattenuated lesions on immediate NCCT after mechanical thrombectomy. $J$ Neurointerv Surg. 2020;12(2):127-131. doi:10.1136/neurintsurg-2019-014846

76. John S, Hazaa W, Uchino K, et al. Timeline of blood pressure changes after intra-arterial therapy for acute ischemic stroke based on recanalization status. J Neurointerv Surg. 2017;9(5):455-458. doi:10.1136/neurintsurg-2016-012369

77. Martins AI, Sargento-Freitas J, Silva F, et al. Recanalization modulates association between blood pressure and functional outcome in acute ischemic stroke. Stroke. 2016;47(6):1571-1576. doi:10.1161/ STROKEAHA.115.012544

78. Matusevicius M, Cooray C, Bottai M, et al. Blood pressure after endovascular thrombectomy: modeling for outcomes based on recanalization status. Stroke. 2020;51(2):519-525. doi:10.1161/ STROKEAHA.119.026914

79. Maier IL, Tsogkas I, Behme D, et al. High systolic blood pressure after successful endovascular treatment affects early functional outcome in acute ischemic stroke. Cerebrovasc Dis. 2018;45(1-2):1825. doi: $10.1159 / 000484720$
80. Bai J, Lyden PD. Revisiting cerebral postischemic reperfusion injury: new insights in understanding reperfusion failure, hemorrhage, and edema. Int J Stroke. 2015;10(2):143-152. doi:10.1111/ijs.12434

81. Dalkara T, Arsava EM. Can restoring incomplete microcirculatory reperfusion improve stroke outcome after thrombolysis? J Cereb Blood Flow Metab. 2012;32(12):2091-2099. doi:10.1038/ jcbfm.2012.139

82. Tomsick T. TIMI, TIBI, TICI: i came, i saw, i got confused. AJNR Am J Neuroradiol. 2007;28(2):382-384.

83. Eilaghi A, Brooks J, d'Esterre C, et al. Reperfusion is a stronger predictor of good clinical outcome than recanalization in ischemic stroke. Radiology. 2013;269(1):240-248. doi:10.1148/ radiol.13122327

84. Zhang JH, Obenaus A, Liebeskind DS, et al. Recanalization, reperfusion, and recirculation in stroke. J Cereb Blood Flow Metab. 2017;37 (12):3818-3823. doi:10.1177/0271678X17732695

85. Mistry EA, Sucharew H, Mistry AM, et al. Blood Pressure after Endovascular Therapy for Ischemic Stroke (BEST): a Multicenter Prospective Cohort Study. Stroke. 2019;50(12):3449-3455.

86. Liu K, Yan S, Zhang S, et al. Systolic blood pressure variability is associated with severe hemorrhagic transformation in the early stage after thrombolysis. Transl Stroke Res. 2016;7(3):186-191. doi:10.1007/s12975-016-0458-6

87. Manning LS, Mistri AK, Potter J, et al. Short-term blood pressure variability in acute stroke: post hoc analysis of the controlling hypertension and hypotension immediately post stroke and continue or stop post-stroke antihypertensives collaborative study trials. Stroke. 2015;46(6):1518-1524. doi:10.1161/STROKEAHA.115.009078

88. Manning LS, Rothwell PM, Potter JF, et al. Prognostic significance of short-term blood pressure variability in acute stroke. Stroke. 2015;46 (9):2482-2490. doi:10.1161/STROKEAHA.115.010075

89. Shi Z, Li ES, Zhong JS, et al. Predictive significance of day-to-day blood pressure variability in acute ischemic stroke for 12-month functional outcomes. Am $J$ Hypertens. 2017;30(5):524-531. doi:10.1093/ajh/hpx005

90. Wang Y, Wang JE, Meng P, et al. Mid-term blood pressure variability is associated with clinical outcome after ischemic stroke. Am J Hypertens. 2017;30(10):968-977.

91. Chung J-W, Kim N, Kang J, et al. Blood pressure variability and the development of early neurological deterioration following acute ischemic stroke. J Hypertens. 2015;33(10):2099-2106. doi:10.1097/ HJH.0000000000000675

92. Buratti L, Cagnetti C, Balucani C, et al. Blood pressure variability and stroke outcome in patients with internal carotid artery occlusion. J Neurol Sci. 2014;339(1-2):164-168. doi:10.1016/j.jns.2014.02.007

93. Zhang T, Wang X, Wen C, et al. Effect of short-term blood pressure variability on functional outcome after intra-arterial treatment in acute stroke patients with large-vessel occlusion. BMC Neurol. 2019;19(1):228. doi:10.1186/s12883-019-1457-5

94. Mistry EA, Mehta T, Mistry A, et al. Blood pressure variability and neurologic outcome after endovascular thrombectomy: a secondary analysis of the BEST Study. Stroke. 2020;51(2):511-518. doi:10.1161/STROKEAHA.119.027549

95. Kim TJ, Park HK, Kim JM, et al. Blood pressure variability and hemorrhagic transformation in patients with successful recanalization after endovascular recanalization therapy: a retrospective observational study. Ann Neurol. 2019;85(4):574-581. 


\section{Publish your work in this journal}

Risk Management and Healthcare Policy is an international, peerreviewed, open access journal focusing on all aspects of public health, policy, and preventative measures to promote good health and improve morbidity and mortality in the population. The journal welcomes submitted papers covering original research, basic science, clinical \& epidemiological studies, reviews and evaluations, guidelines, expert opinion and commentary, case reports and extended reports. The manuscript management system is completely online and includes a very quick and fair peer-review system, which is all easy to use. Visit http://www.dovepress.com/testimonials.php to read real quotes from published authors.

Submit your manuscript here: https://www.dovepress.com/risk-management-and-healthcare-policy-journal 